\title{
World Environment Day: Beat Plastic Pollution
}

As the co-editor of IHRJ, this is the second editorial that I am writing for our readers on the important occasion of world environment day, which is indeed an honour which humbles me to the core. My heartfelt gratitude to the editorial team and I sincerely appreciate their hard work that produces quality articles month after month.

World environment day is celebrated every year on $5^{\text {th }}$ of June. The inception of this event was in the year 1974 and is widely celebrated in over 100 countries with the aim to provide the world a better living environment that is in harmony with mother nature. Every year, a host and a theme is selected, which focuses attention on a particularly pressing environmental concern. The host for this year was India, and the theme chosen was: beat plastic pollution.

Plastic pollution since a long time has been an important concern. The World Health Organisation (WHO) states that every year, people across the globe throw away enough plastic to circle the Earth a whopping four times! It has also been stated that much of that waste doesn't make it into a landfill, is dumped in oceans and causes the death of about one million seabirds and 100,00o marine mammals every year. Another interesting quote is: "If you cannot reuse it, refuse it" ${ }^{\prime \prime}$ which is very apt and needs to be followed by each and every person.

Following the principle of "out of sight, out of mind", it was not until the year 1997, when Capt. Charles Moore first publicly reported sights of swirling masses of plastic (called the great plastic garbage patch or gyres) in the Pacific Ocean bringing media attention to this phenomenon. It is said that by the year 2050, if the same pace of dumping plastic continues, the oceans will have more plastic than fish. The sea animals suffer because of these plastic dumplings. Leaching of harmful substances (e.g. Biphenyl A as it decomposes) poisons them. ${ }^{2}$ There have been instances when sharp plastic pieces gravely injure these animals. These animals are at times stuck in discarded plastic fishing nets which leads to their death. One such disaster worth mentioning is the
Deep-water Horizon oil spill of 2010, also called Gulf of Mexico oil spill of 2010, which is considered to be one of the largest marine oil spill in history. It was caused by an explosion on the deep-water Horizon oil rig-located in the Gulf of Mexico on April 20 ${ }^{\text {th }}, 2010$ leading to its subsequent sinking on April 22 ${ }^{\text {nd }}$. By the time the well was sealed months later, about 5 million barrels of oil had spilled into the gulf, killing a large number of marine animals. ${ }^{2}$

It is worth noting that recycling takes approximately $88 \%$ less energy as compared to making new plastic. Steps should be taken in the right direction by refusing single use plastics (disposable glasses, spoons, water bottles, single serve food packing, etc.) and disposable plastics. This global movement can start from our homes itself.

\section{REFERENCES}

1. $\quad$ http://worldenvironmentday.global/en/newscategory/beat-plastic-pollution

2. https://naturalenergyhub.com/pollution/plasticpollution-causes-effects/ 
Source of support: Nil, Conflict of interest: None declared

Cite this article as:

Thakar S. World Environment Day: Beat Plastic Pollution. Int Healthcare Res J 2018;2(3):50-51. doi: 10.26440/IHRJ/02_03/170

Dr. Sahil Thakar

Co-editor

International Healthcare Research Journal (IHRJ)

\section{Dr. Sahil Thakar}

G-105

AWHO Society

Sector 27

Panchkula 134116
For article enquiry/author contact details, e-mail at: manuscriptenquiry.ihrj@gmail.com 